\title{
Konseling dan Promosi Kesehatan untuk Pencegahan Hipertensi bagi Masyarakat Dukuh Bintaran, Bantul, DIY
}

\author{
Sulistyawati ${ }^{1}$ \\ ${ }^{1}$ Universitas Ahmad Dahlan
}

\begin{abstract}
Article History ABSTRACT
Received 26.12.2018

Received in revised form 22.04.2019

Accepted 26.07.2019

Available online 20.08.2019

HEALTH COUNSELING AND PROMOTION IN THE PREVENTION OF HYPERTENSION FOR THE COMMUNITY OF BINTARAN HAMLET, BANTUL, DIY. Hypertension is a condition of increased blood pressure in arteries that increase the cause of the heart to work more than usual to circulate blood through the blood vessels. Precautions if not properly treated will cause other diseases such as sroke. This dedication is carried out with active lectures and discussions with participants. From these activities it is known that people already know the hypertension and the way of prevention but difficult to realize in everyday life. So, in the future there should be a creative health promotion effort and target the right people / groups that can bring about change.
\end{abstract}

KEYWORDS: Healthy Living, Hypertension Counseling, Prevention. Attribution 4.0 International License, which permits unrestricted use, distribution, and reproduction in any medium, provided the original work is properly cited. (c) 2019 Sulistyawati.

\section{PENDAHULUAN}

Program Indonesia Sehat merupakan salah satu program dari agenda ke-5 Nawa Cita yang dilaksanakan pada masa pemerintahan Presiden Joko Widodo. Program Indonesia Sehat bertujuan untuk meningkatkan kualitas hidup manusia Indonesia. Selain itu Program Indonesia Sehat didukung oleh program sektoral lainnya yaitu Program Indonesia Pintar. Program Indonesia Kerja, dan Program Indonesia Sejahtera. Program Indonesia Sehat selanjutnya menjadi program utama Pembangunan Kesehatan yang kemudian direncanakan pencapaiannya melalui Rencana Strategis (Renstra) Kementerian Kesehatan Tahun 2015-2019, yang ditetapkan melalui Keputusan Menteri Kesehatan R.I. Nomor HK.02.02/Menkes/52/2015 (Kementerian Kesehatan Republik Indonesia, 2015).

Program Indonesia Sehat Pendekatan Keluarga (PISPK) memiliki dua belas indikator utama yang telah ditetapkan sebagai penanda status kesehatan sebuah keluarga. Dua belas indikator utama yang meliputi (1) keluarga mengikuti program

*) Corresponding author: Fakultas Kesehatan Masyarakat. UAD Kampus 3. Jl. Prof. Dr. Soepomo, Janturan, Umbulharjo, Yogyakarta, Indonesia; Email: sulistyawatisuyanto@gmail.com 
Keluarga Berencana, (2) Ibu melakukan persalinan di fasilitas kesehatan, (3) bayi mendapat imunisasi dasar lengkap, (4) bayi mendapat air susu ibu (ASI) eksklusif, (5) balita mendapatkan pemantauan pertumbuhan, (6) penderita tuberculosis paru mendapatkan pengobatan sesuai standar, (7) penderita hipertensi melakukan pengobatan secara teratur, (8) penderita gangguan jiwa mendapatkan pengobatan dan tidak ditelantarkan, (9) anggota keluarga tidak ada yang merokok, (10) keluarga sudah menjadi anggota Jaminan Kesehatan Nasional (JKN), (11) keluarga mempunyai akses sarana air bersih, (12) keluarga mempunyai akses atau menggunakan jamban. Keadaan masingmasing indikator, mencerminkan kondisi PHBS dari keluarga yang bersangkutan. Pemerintah Daerah dapat menetapkan indicator tambahan selain indicator utama sesuai dengan kondisi dan kebutuhan daerah (Kementerian Kesehatan Republik Indonesia, 2015).

Salah satu Puskesmas yang melaksanakan PIS-PK adalah Puskesmas Banguntapan 1 yang mempunyai jumlah desa binaan sejumlah 3 desa. Desa tersebut antara lain Desa Baturetno (8 dusun), Desa Potorono (9 dusun), Desa Jambidan (7 dusun). Pengambilan data PIS-PK dilakukan di Desa Jambidan pada Dusun Kepanjen RT 01dan 02 dengan jumlah KK yaitu 107 KK. Berdasarkan pendataan PIS-PK yang dilakukan oleh Mahasiswa Fakultas Kesehatan Masyarakat Universitas Ahmad Dahlan dalam Praktek Belajar Lapangan 1 di Desa Jambidan dan Dusun Kepanjen Rt 01 dan 02 didapatkan hasil bahwa dari 12 indikator PISPK, hipertensi menjadi prioritas utama permasalahan. Penentuan prioritas masalah tersebut dilakukan dengan metode perhitungan urgency, seriousness, growht, and facilitate.

Hipertensi merupakan kondisi tekanan darah di arteri meningkat peningkatan ini menyebabkan jantung harus bekerja lebih dari biasanya untuk mengedarkan darah melalui pembuluh darah. Tekanan darah melibatkan dua pengukuran, yaitu sistolik dan diastolik (Guiton \& Ehall, 2006) dan (WHO, 2018). Tekanan darah normal pada saat istirahat adalah dalam kisaran sistolik $100-140 \mathrm{mmHg}$ dan diastolik 60-90 mmHg.Tekanan darah tinggi terjadi bila tekanan darah terus-menerus berada pada $140 / 90 \mathrm{mmHg}$ atau lebih (Sidartawan, 2009).

World Health Organization (WHO) menyebutkan bahwa hipertensi menyebabkan 7.5 juta kematian di penjuru dunia atau sekitar $12.8 \%$ dari total kematian yang ada. Selain itu hipertensi ini merupakan penyebab utama penyakit lainnya yaitu serangan jantung koroner dan serangan sroke. Disebutkan juga bahwa pada tahun 2008, insidensi hipertensi pada orang dewasa di atas 25 tahun sebesar 40\% (WHO, 2018).

Kabupaten Bantul merupakan salah satu kabupaten yang berkontribusi terhadap kasus hipertensi di Daerah Istimewa Yogyakarta (DIY). Hipertensi termasuk dalam sepuluh besar penyakit di Kabupaten Bantul, dimana pada tahun 2016 di Kabupaten Bantul sebanyak 44.947 kasus dari seluruh wilayah Kecamatan yang berada di Kabupaten Bantul (Dinas Kesehatan Kabupaten Bantul, 2017). Sementara itu diantara Puskesmas yang lain, Puskesmas Banguntapan 1 memiliki kasus hipertensi sebanyak 6.981 kasus pada tahun 2015 yaitu menduduki peringkat kedua di Puskesmas Banguntapan 1 (Dinas Kesehatan Kabupaten Bantul, 2016).

Berdasarkan beberapa situasi tersebut, yaitu data PIS-PK dan data-data sekunder yang lain, maka kiranya edukasi dan penyuluhan tentang hipertensi perlu diberikan kepada warga masyarakat yang ada di wilayah kerja Puskesmas Banguntapan 1, 
termasuk di Dusun Bintaran, Jambidan. Tujuan dari pengabdian masyarakat ini adalah menyampaikan materi edukasi terkait hipertensi kepada masyarakat setempat. Dengan harapan masyarakat semakin sering terpapar dengan hipertensi sehingg mampu melakukan pencegahan secara mandiri dan dini.

\section{METODE PELAKSANAAN}

Pengabdian masyarakat ini merupakan bentuk edukasi kepada masyarakat dalam hal pencegahan penyakit Hipertensi. Tujuan utama dari kegiatan ini adalah meningkatkan pemahaman masyarakat tentang sebab dan pencegahan yang dapat dilakukan secara dini. Edukasi dilakukan secara secara aktif antara narasumber dan peserta. Power point dan leaflet digunakan sebagai media edukasi kepada masyarakat. Komposisi pengabdian ini adalah 50\% ceramah dan 50\% diskusi.

Pada pengabdian ini disampaikan tiga hal utama yaitu: 1) definisi ilmiah hipertensi, 2) penyebab hipertensi, 3) gejala hipertensi, 4) usaha pencegahan yang bisa ditempuh oleh masyarakat.

\section{HASIL DAN PEMBAHASAN}

Kegiatan ini telah dilaksanakan pada tanggal 27 Mei 2018 di rumah ketua RT 1 dan RT 2, Dusun Bintaran, Desa Jambidan, Banguntapan Bantul. Sebanyak 28 ibu rumah tangga dari RT 1 dan 48 ibu rumah tangga dari RT 2 berpartisipasi dalam kegiatan ini.

Penyuluhan diawali dengan tanya jawab (Gambar 3), dengan tujuan brainstorming apa yang dimaksud dengan hipertensi, gejala dan penyebabnya. Dari proses tersebut dapat diketahui bahwa masyarakat sudah akrab dengan definisi hipertensi dan gejalanya. Masyarakat mendapat informasi tersebut dari Puskesmas setempat ataupun melalui Posyandu lansia di wilayah tersebut. Namun demikian, usaha pencegahan dirasa masih sulit karena berkaitan dengan gaya hidup (lifestyle) yang tidak bias diubah secara instan. Oleh sebab itu sering ditemukan bahwa warga masyarakat yang terserang hipertensi tidak mengetahui secara dini (tidak terdiagnosis) sejak awal.

Selanjutnya peserta diberikan pengertian hipertensi secara umum dengan bahasa awam yang mudah dipahami. Kemudian dimulai dengan bahaya hipertensi yaitu, bahwa penyakit ini merupakan penyakit yang mematikan dan bahkan angkanya menempati peringkat ketujuh dalam 10 besar penyakit di Indonesia pada tahun 2010 (Kementerian Kesehatan RI, 2012). Selain itu juga disampaikan data bahwa pada tahun 2013 terdapat $25.8 \%$ penderita hipertensi, dimana 2/3 diantaranya tidak terdiagnosa (Biro Komunikasi dan Pelayanan Masyarakat Kementerian Kesehatan RI, 2017). Pengetahuan ini penting diberikan kepada peserta untuk menarik ketertarikan dan memberikan awareness atau kewaspadaan bahwa hipertensi merupakan penyakit yang berbahaya dan harus diwaspadai karena bisa jadi tidak terdiagnosis. Suasana penyuluhan terlihat pada Gambar 1 dan Gambar 2.

Tahap selanjutnya disampaikan berbagai faktor yang mungkin menjadi penyebab terjadinya hipertensi antara lain: konsumsi rokok, kopi, makanan asin (garam), semua dalam konteks jika berlebihan. Sebagian besar para peserta yang merupakan ibu rumah tangga mengetahui bahwa konsumsi rokok dan kopi baik itu oleh dirinya sendiri maupun sanak keluarga yang lain merupakan kebiasaan yang tidak baik dan berpotensi untuk 
menimbulkan hipertensi. Namun demikian, mereka mengatakan sulit untuk memberikan peringatan atau pemahaman kepada anggota keluarga tersebut. Hal ini menurut mereka karena kopi dan rokok merupakan dua hal umum yang dikonsumsi masyarakat. Sehingga mereka berharap pihak-pihak terkait lebih menggaris bawahi dalam setiap kampanye atau sosialisasi bahwa 2 hal yang umum tersebut berpotensi berbahaya bagi konsumennya.

Rokok merupakan suatu bahan yang mengandung zat adiktif, biasa disebut dengan nikotin. Rokok dapat membahayakan seluruh anggota tubuh, terutama jika dikonsumsi dengan zat berbahaya yang lain seperti alkohol. Hal itu dapat meningkatkan risiko terserang penyakit. Masalah rokok sesungguhnya tidak hanya terjadi di Indonesia. Di negara maju sekalipun, rokok menjadi gaya hidup yang sulit dihindari. Seperti yang dilaporkan oleh Centre for Disease Control and Prevention (CDC) bahwa rokok di Amerika Serikat diperkirakan menyebabkan kematian sebanyak 480.000 setiap tahunnya (Centre for Disease Control and Prevention, 2017).

Selanjutnya tentang kopi dimana didalamnya mengandung caffein. Disampaikan kepada peserta bahwa stigma kopi berbahaya bagi kesehatan harus ditempatkan pada porsi yang sesuai. Hal ini agar peserta tidak mensamaratakan bahwa minum kopi akan selalu berakhir dengan hipertensi. Pada masa sekarang ini kopi menjadi bagian gaya hidup yang tidak bisa terpisahkan. Hal ini karena kopi difungsikan sebagai penahan kantuk atau penambah semangat bagi orang yang umumnya bekerja. Dengan demikian konsep kopi berbahaya harus disampaikan secara bijak. Hal ini didukung oleh kajian yang menelusuri tentang efek kopi pada kesehatan manusia, yang menyebutkan bahwa tidak semua konsumsi kopi berdampak buruk, namun kopi juga bisa bermanfaat jika tidak berlebihan (ÖZPALAS \& ÖZER, 2017).

Pada pembicaraan selanjutnya dibahas tentang kebiasaan mengkonsumsi garam dan makanan asing yang lain. Peserta yang hadir menyebutkan bahwa hal itu juga sulit dihindari. Sebagai ibu rumah tangga yang bertanggung jawab untuk menyiapkan makanan, acapkali menemukan dilema. Bahwa keluarga terbiasa mengkonsumsi masakan dengan menggunakan garam, sehingga jika masakan tidak diberi garam maka makanan "tidak akan laku" atau dengan kata lain tidak dimakan karena dirasa tidak enak. Sehingga untuk kasus seperti ini memerlukan perubahan pola hidup dalam jangka panjang. Hal ini juga sesuai dengan teori perilaku bahwa perubahan perilaku tidak bisa dilakukan secara singkat. Suatu penelitian menyebutkan bahwa perubahan perilaku seseorang akan sangat tergantung pada kepribadian, perilaku dan situasinya. Penelitian tersebut juga menyebutkan suatu perilaku baru akan terbentuk minimum 18 hari jika dilakukan secara konsisten dan bisa lebih lama tergantung kondisi seseorang tersebut (Clear, 2018). Dengan demikian, dalam konteks ini, peserta disarankan konsisten terhadap usaha pencegahan konsumsi garam secara terus menerus.

Mendekati akhir sesi, disampaikan bagaimana usaha pencegahan yang bisa dilakukan untuk mencegah hipertensi. Hal yang dianjurkan adalah dengan menjaga berat badan ideal yaitu mencegah overweight maupun kekurangan berat badan. Pencegahan tersebut bisa dilakukan dengan mengkontrol asupan makanan yang dimasukkan ke dalam tubuh. 


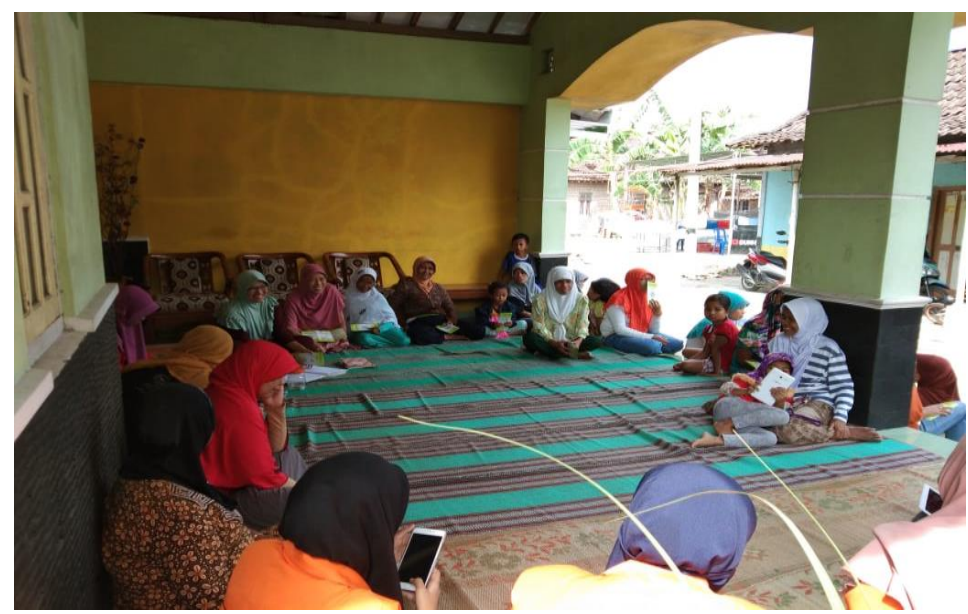

Gambar 1. Suasana Penyuluhan di RT 2

Pencegahan yang kedua adalah dengan memiliki kebiasaan berolah raga. Kebiasaan ini umumnya tidak dimiliki oleh ibu rumah tangga yang berada pada wilayah peralihan dari desa ke kota, sehingga mereka tidak memiliki jadwal rutin olahraga karena kesibukan bekerja. Peserta yang hadir menyampaikan bahwa tidak ada waktu dan sarana yang terbatas untuk berolahraga.

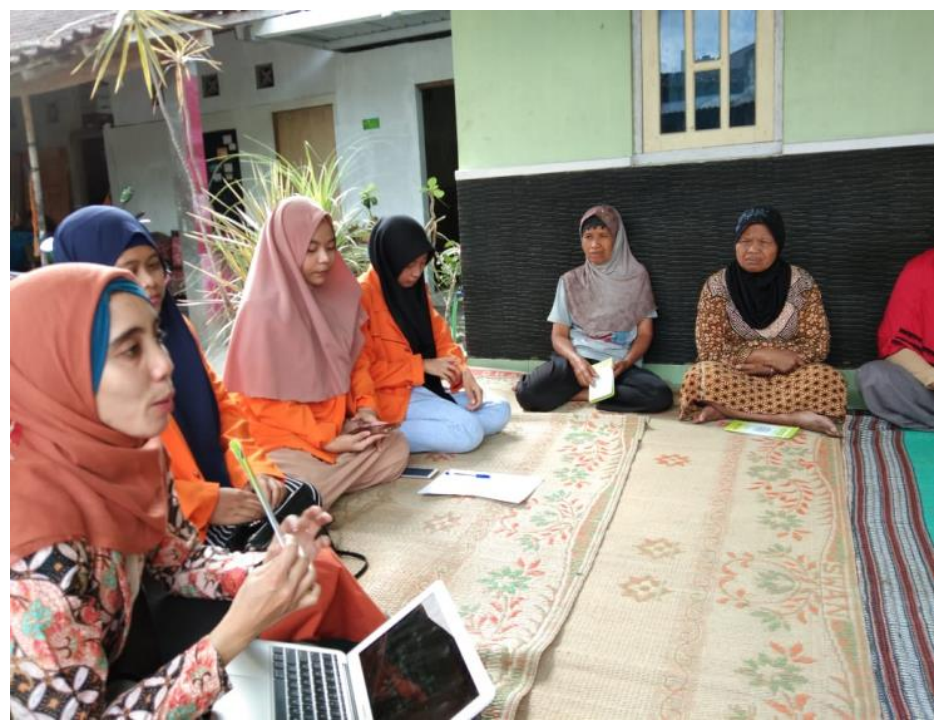

Gambar 2. Penyampaian Materi di RT 1

Secara umum olahraga atau latihan fisik merupakan aktifitas yang baik bagi kesehatan tubuh manusia dan tidak hanya berkaitan dengan hipertensi semata. Terdapat beberapa alasan mengapa manusia harus menjalankan latihan fisik secara rutin, antara lain: 1) olah raga dapat menjaga mood seseorang agar terhindar dari stress, depresi dan marah, 2) olahraga dapat dijadikan sarana untuk menjaga fitalitas dan selalu bugar, 3) menghindari konsumsi obat-obatan, hal ini dapat terjadi jika kita sehat maka tidak perlu berkunjung ke dokter untuk berobat (American Hearth Association, 2017). 


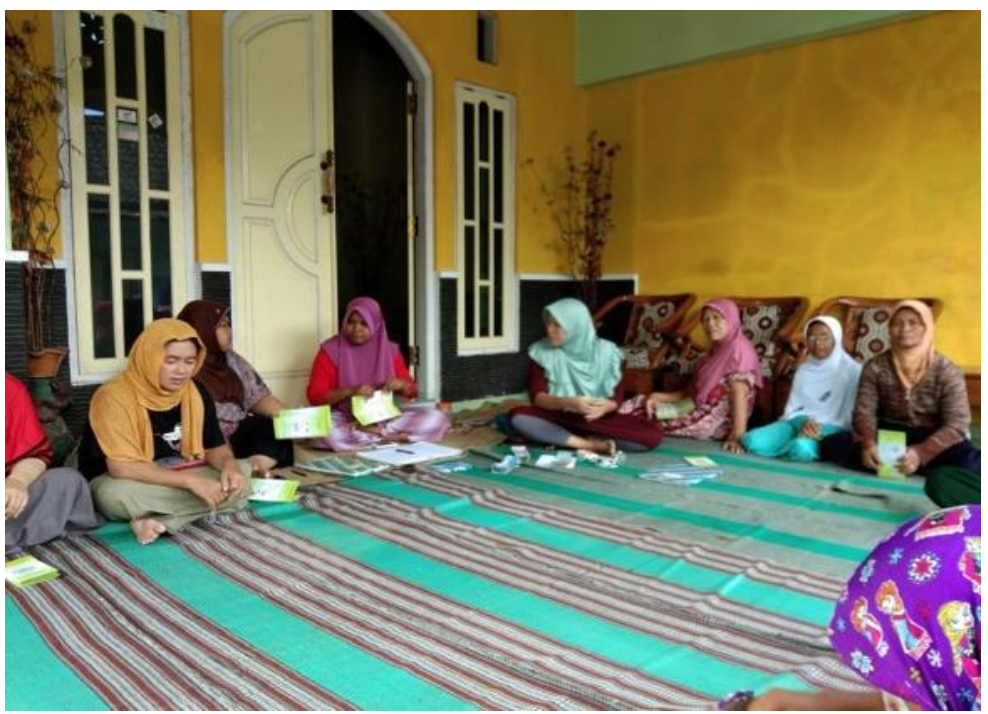

Gambar 3. Suasana Tanya Jawab di RT 2

Pencegahan yang ketiga adalah mengurangi atau menghilangkan konsumsi rokok dan kopi. Hal ini juga berlaku untuk keluarga peserta. Hal ini mengingat jika dalam satu keluarga yang lain terdapat yang anggota yang sakit maka akan mengakibatkan penurunan kualitas hidup anggota keluarga yang lain (Golics, Khurshid, Basra, Salek, \& Finlay, 2013). Hal inilah yang ditekankan kepada peserta bahwa jika ada anggota keluarga yang sakit maka yang merasakan lelah dan sakit tentu tidak hanya si pasien namun juga anggota keluarga yang lain.

Usaha pencegahan yang terakhir adalah memantau tekanan darah secara rutin. Hal ini bertujuan untuk mengetahui kondisi terkini dan dapat diambil tindakan jika terjadi kenaikan tekanan darah hingga melampaui batas normal. Hal ini dapat dilakukan dengan mengunjungi puskesmas atau bidan terdekat. Cara ini juga dianjurkan oleh praktisi kesehatan sebagai cara yang efektif untuk mencegah hipertensi (McCoy, 2016).

Dari kegiatan dapat diambil suatu makna bahwa, masyarakat sudah memiliki pengetahuan yang memadai tentang hipertensi dari berbagai sumber, seperti keluarga, kader kesehatan, posyandu lansia maupun dari puskesmas. Namun demikian realisasi atau praktek dalam kehidupan sehari-hari masih rendah dengan berbagai alasan. Dari kenyataan tersebut, usaha promosi kesehatan yang selama ini sudah dilakukan perlu dipertahankan dan ditingkatkan dengan menyasar masyarakat yang sesuai dengan frekuensi yang kontinyu atau terus menerus sehingga paparan masyarakat terhadap materi tersebut menjadi semakin sering.

\section{SIMPULAN}

Berdasarkan pelaksanaan kegiatan ini dapat disimpulkan bahwa hipertensi merupakan masalah yang umum menyerang masyarakat namun karena berkaitan dengan lifestyle, sehingga gerakan pencegahan sulit dilakukan. Hal yang bisa ditempuh adalah dengan edukasi generasi muda saat ini, secara dini, untuk tidak melakukan atau mengkonsumsi hal-hal yang dapat memicu hipertensi. Hal ini dikarenakan jika usaha pencegahan dilaksanakan sudah pada usia lanjut (dewasa), realisasinya lebih sulit, seperti halnya yang dijumpai pada generasi saat ini yang sulit meninggalkan lifestyle pemicu 
hipertensi. Usaha promosi kesehatan yang sudah dilakukan Puskesmas selama ini perlu digiatkan kembali dengan perubahan metode dan sasaran yang lebih tepat.

\section{REFERENSI}

American Hearth Association. (2017). Why is physical activity so important for health and wellbeing?. Retrieved November 20, 2018, from https://www.heart.org/en/healthyliving/fitness/fitness-basics/why-is-physical-activity-so-important-for-health-andwellbeing

Biro Komunikasi dan Pelayanan Masyarakat Kementerian Kesehatan RI. (2017). Sebagian besar penderita hipertensi tidak menyadarinya. Retrieved November 19, 2018, from http://www.depkes.go.id/article/view/17051800002/sebagian-besar-penderitahipertensi-tidak-menyadarinya.html

Centre for Disease Control and Prevention. (2017). Health Effects of Cigarette Smoking. Retrieved November 19, 2018, from https://www.cdc.gov/tobacco/data_statistics/fact_sheets/health_effects/effects_cig_s moking/index.htm

Clear, J. (2018). How Long Does it Actually Take to Form a New Habit? (Backed by Science). Retrieved November 19, 2018, from https://jamesclear.com/new-habit

Dinas Kesehatan Kabupaten Bantul. (2016). Profil Puskesmas Banguntapan I. Data Tahun 2015. Bantul: Dinkes Kab. Bantul.

Dinas Kesehatan Kabupaten Bantul. (2017). Profil Kesehatan Kabupaten Bantul tahun 2017. Bantul: Dinkes Kab. Bantul. doi: 10.3406/arch.1977.1322

Golics, C. J., Khurshid, M., Basra, A., Salek, M. S., \& Finlay, A. Y. (2013). The impact of patients' chronic disease on family quality of life: An experience from 26 specialties. International Journal of General Medicine, 6, 787-798. doi: 10.2147/IJGM.S45156

Guiton, A. C., \& Ehall, J. (2006). Buku ajar psikologi kedokteran (11th ed.). Jakarta: EKG.

Kementerian Kesehatan RI. (2015). Rencana Strategis Kementerian Kesehatan tahun 20152019. Jakarta: Kementerian Kesehatan Republik Indonesia.

Kementerian Kesehatan RI. (2012). Penyakit tidak menular. Jakarta: Kementerian Kesehatan Republik Indonesia.

McCoy, K. (2016). 6 ways to prevent hypertension. Retrieved November 19, 2018, from https://www.everydayhealth.com/hypertension/preventing.aspx

Özpalas, B., \& Özer, E. A. (2017). Kafeinin İnsan Sağlığı Üzerindeki Etkileri. Nevş̧ehir Bilim ve Teknoloji Dergisi, 6, 297-305. doi: 10.17100/nevbiltek.331845 
Jurnal Pengabdian Pada Masyarakat 2019, 4(2), 187-194

Sidartawan. (2009). Buku ajar ilmu penyakit dalam. Jakarta: International Publishing.

WHO. (2018). Raised blood pressure. Retrieved November 17, 2018, from http://www.who.int/gho/ncd/risk_factors/blood_pressure_prevalence_text/en/ 